\title{
Quantitative analysis of vitamin D using m/MALDI-TOF mass spectrometry based on a parylene matrix chip
}

\author{
Joo-Yoon Noh', Moon-Ju Kim', Jong-Min Park', Tae Gyeong Yun ${ }^{1}$, Min-Jung Kang ${ }^{2}$ and Jae-Chul Pyun ${ }^{1 *}$ (1)
}

\begin{abstract}
Vitamin D deficiency is associated with various disorders and is diagnosed based on the concentration of 25-hydroxy vitamin $\mathrm{D} 3\left(25(\mathrm{OH}) \mathrm{D}_{3}\right)$ in serum. The parylene matrix chip was fabricated to reduce the matrix background noise, and the homogenous distribution of the matrix was retained for the quantitative analysis of $25(\mathrm{OH}) \mathrm{D}_{3}$. The Amplex Red assay was performed to confirm that the sample-matrix mixing zone of the parylene matrix chip was formed below the surface of the parylene- $\mathrm{N}$ film. The homogeneous distribution of the matrix was verified from the fluorescence image. For effective analysis using a parylene matrix chip, $25(\mathrm{OH}) \mathrm{D}_{3}$ was modified through the nucleophilic addition of betaine aldehyde (BA) to form a hemiacetal salt. Such modified $25(\mathrm{OH}) \mathrm{D}_{3}$ with a positive charge from $\mathrm{BA}$ could be effectively analyzed using MALDI-TOF mass spectrometry. Serum $25(\mathrm{OH}) \mathrm{D}_{3}$ was extracted by liquid-liquid extraction (LLE) and quantified using MALDI-TOF mass spectrometry based on the parylene matrix chip. The intensity of the mass peak of $25(\mathrm{OH}) \mathrm{D}_{3}$ was linearly correlated $\left(r^{2}=0.992\right)$ with the concentration of $25(\mathrm{OH}) \mathrm{D}_{3}$ spiked in serum, and the LOD was $0.0056 \mathrm{pmol} / \mu \mathrm{L}$. Energy drinks and vitamin $\mathrm{D}_{3}$ tablets were also employed for the real sample analysis. Finally, the results of the chemiluminescence binding assay and MALDI-TOF mass spectrometry were statistically analyzed to determine the applicability of the method using the Bland-Altman test and Passing-Bablok regression.
\end{abstract}

Keywords: MALDI-TOF mass spectrometry, Vitamin D, Parylene matrix chip, Serum analysis

\section{Introduction}

Vitamin D, a fat-soluble secosteroid prohormone, helps maintain calcium/phosphate homeostasis and is essential for bone and muscle metabolism (Ahn et al. 2020; Fleet 2017; Smith et al. 2020). Vitamin D has been analyzed in two different chemical forms: (1) naturally occurring vitamin $\mathrm{D}_{3}$ in mammals and (2) vitamin $\mathrm{D}_{2}$ derived from plant sources and chemical synthesis (Ding et al. 2010). Human vitamin $D_{3}$ is predominantly synthesized in the skin via UV exposure through the conversion of 7-dehydrocholesterol to vitamin $\mathrm{D}_{3}$ (Loser and Beissert 2009). Deficient or excess vitamin D is linked to various

\footnotetext{
*Correspondence: jcpyun@yonsei.ac.kr

${ }^{1}$ Department of Materials Science and Engineering, Yonsei University, 134

Shinchon-dong, Seodaemun-gu, Seoul 120-749, Korea

Full list of author information is available at the end of the article
}

disorders, such as rickets, osteomalacia, cardiovascular diseases, neurodegenerative diseases, diabetes, and even cancer. Vitamin D has been used as a biomarker for the early diagnosis of many disorders (Holick 2007; Holick and Chen 2008). In particular, 25-hydroxycholecalciferol $\left(25(\mathrm{OH}) \mathrm{D}_{3}\right)$ has been used as a clinical biomarker for monitoring vitamin $\mathrm{D}$ status owing to its direct link to the vitamin D substrate, a long half-life, and a high concentration in blood (Ding et al. 2010; Zerwekh 2008). The cut-off concentration of $25(\mathrm{OH}) \mathrm{D}_{3}$ for vitamin D deficiency is reported to be less than $10 \mathrm{ng} / \mathrm{mL}(0.026 \mathrm{pmol} /$ $\mu \mathrm{L}$ ) in serum (Kamen et al. 2006). For the quantification of $25(\mathrm{OH}) \mathrm{D}_{3}$ in blood, enzyme-linked immunosorbent assay (ELISA) and liquid chromatography-tandem mass spectrometry (LC-MS/MS) serve as the standard techniques (Choi et al. 2020; Hollis and Napoli 1985; Jenkinson et al. 2016; Kim et al. 2017a). However, these 
techniques are rather time-consuming (ELISA: 1-2 h, LC-MS/MS: $5 \mathrm{~min}$ ), have low sensitivity $(2.5-5.5 \mathrm{ng} /$ $\mathrm{mL}$ ), and require highly specialized instruments and specific antibodies (Zerwekh 2004).

Matrix-assisted laser desorption/ionization time-offlight mass spectrometry (MALDI-TOF MS) has been widely used for the analysis of biomolecules through mild ionization using organic matrix molecules, such as $\alpha$-cyano-4-hydroxycinnamic acid (CHCA) and 2, 5-dihydroxybenzoic acid (DHB). The MALDI-TOF MS has significant advantages over LC-MS/MS because LC-MS/ MS requires relatively large amounts of samples (more than $50 \mu \mathrm{L}$ ) and produces waste solvent and it is also difficult to automate (Enko et al. 2015). Additionally, electrospray ionization (ESI) source which is commonly coupled with LC-MS/MS (LC-ESI-MS/MS) produces peaks of multi-protonated ions for mixtures. However, the application of conventional MALDI-TOF mass spectrometry has been limited for the quantitative analysis of small molecules with low molecular weight $(\mathrm{m} / z$ of less than 500) (Guo et al. 2002; Wei et al. 1999). Such limitation is caused by the fracture of organic matrix molecules, which produce unreproducible ions in the $\mathrm{m} / \mathrm{z}$ range of 500 (Kim et al. 2017b, 2014a, 2014b; Park et al. 2017). The organic matrix molecules produced unreproducible mass peaks, as observed in the repeated measurements, even at the same sample spot (only with a conventional matrix of CHCA). Additionally, the inhomogeneous crystal formation of the matrix-analyte mixture caused difficulty in the quantitative analysis (Cohen and Gusev 2002). To solve such problems, a parylene matrix chip was recently developed for the quantitative analysis of small molecules in the low $m / z$ range of less than 500 . When a parylene film with a thickness of less than $50 \mathrm{~nm}$ was deposited on the dried matrix, the mass peaks from the matrix molecules disappeared. After a sample was dropped and dried on the parylene film, only the mass peaks from the analyte were observed. Based on the properties of the parylene matrix chip, various analytes, such as amino acids and antibiotics, have been quantitatively analyzed using the chip (Kim et al. 2017b, 2014a; Park et al. 2015, 2019, 2020b).

In this study, MALDI-TOF mass spectrometry based on a parylene matrix chip was used for the quantitative analysis of $25(\mathrm{OH}) \mathrm{D}_{3}$. However, the analysis of vitamin $\mathrm{D}$ by MALDI-TOF mass spectrometry (based on the parylene matrix chip) is difficult, as the ionization efficiency of vitamin $D$ is very low due to the hydrophobic nature of vitamin $\mathrm{D}$, which has only few polar functional groups. Additionally, vitamin $\mathrm{D}$ is known to be tightly bound to vitamin $\mathrm{D}$ binding protein (DBP), and the plasma concentrations are reported to be in the low nanomolar range (Shimada et al. 2001). As a result, chemical derivatization methods have been developed for improving detectability of vitamin D (Zaikin and Halket 2006). For effective analysis using a parylene matrix chip, $25(\mathrm{OH}) \mathrm{D}_{3}$ was modified through the nucleophilic addition of betaine aldehyde (BA) to form a hemiacetal salt (Wu et al. 2009). Such modified $25(\mathrm{OH}) \mathrm{D}_{3}$ with a positive charge from BA could be effectively analyzed using MALDI-TOF mass spectrometry based on the parylene matrix chip. In this study, the quantitative analysis of $25(\mathrm{OH}) \mathrm{D}_{3}$ in buffer and human serum will be presented using standard samples. Finally, the analytical results from MALDI-TOF mass spectrometry based on the parylene matrix chip will be statistically compared with those of the conventional analysis method based on an enzyme immunoassay.

\section{Experimental section Materials}

Vitamin $\mathrm{D}_{3}$ (cholecalciferol), 25(OH)D $\mathrm{D}_{3}$ (25-hydroxycholecalciferol), BA chloride, CHCA, ethanol, hexane, acetonitrile, trifluoroacetic acid (TFA), methanol, hydrochloric acid, fluorescein, sodium hydroxide, HRP, luminol, and hydrogen peroxide were purchased from Sigma-Aldrich (St. Louis, MO, USA). The parylene-N precursor was purchased from Femto Science (Hwasung, Korea). Amplex Red reagent was purchased from Invitrogen Molecular Probes (Carlsbad, CA, USA). The MSP 96 stainless steel target plate for Micro Scout MALDI-TOF mass spectrometry was purchased from Bruker Daltonics Co. (Bremen, Germany). Double distilled deionized water $(18 \mathrm{M} \Omega \mathrm{cm})$ was prepared using a Milli-Q purification system (Millipore, Billerica, MA, USA).

\section{Fabrication of the parylene matrix chip}

Parylene matrix chips were developed as described previously (Kim et al. 2017b, 2014a, 2014b; Park et al. 2017). The CHCA matrix was prepared in acetonitrile/0.1\% TFA $(1: 1, \mathrm{v} / \mathrm{v})$ at a concentration of $10 \mathrm{mg} / \mathrm{mL}$, and CHCA solution $(0.7 \mu \mathrm{L})$ was dropped on the stainless-steel plate. Stainless-steel plates with CHCA spots were attached to the MSP 96 stainless steel target plate using silver-nanoparticle-containing adhesive paste for electrical contact.

Thereafter, the parylene- $\mathrm{N}$ thin film was deposited using a thermal parylene coater from Femto Science Co. (Seoul, Korea) by chemical vapor deposition via thermal evaporation of the dimer at $160{ }^{\circ} \mathrm{C}$ and pyrolysis at $650{ }^{\circ} \mathrm{C}$ to generate $\mathrm{p}$-xylylene radicals. Then, parylene $\mathrm{N}$-film was deposited on the target plate under a vacuum below 2 Torr at $25{ }^{\circ} \mathrm{C}$. Finally, the parylene- $\mathrm{N}$ film on the stainless-steel plate with CHCA spots was deposited at room temperature. Further, the thickness of the deposited parylene- $\mathrm{N}$ film was controlled at $60 \mathrm{~nm}$ by adjusting the amount of the parylene- $\mathrm{N}$ dimer powder. 
The porosity of the parylene- $\mathrm{N}$ film was estimated after deposition on a gold layer (thickness $=100 \mathrm{~nm}$ ), which was sputtered on a glass wafer. Cyclic voltammetry (CV) was performed using a gold layer as the working electrode. $\mathrm{CV}$ analysis was performed in $50 \mathrm{mM}$ potassium ferricyanide $\left(\mathrm{K}_{3}\left[\mathrm{Fe}(\mathrm{CN})_{6}\right]_{3}\right)$ at a $\mathrm{pH}$ of 7.0 in the potential range of -400 to $+600 \mathrm{mV}$ (vs. $\mathrm{Ag} / \mathrm{AgCl}$ ) and scan rate of $50 \mathrm{mV} / \mathrm{s}$ using a potentiostat (IVIUM Technologies, Compactstat, Netherlands). CV measurements were repeated three times for each sample, and the third set of data was used as the signal. To validate the mixing zone of the parylene matrix chip, Amplex Red reagent solution $(0.5 \mu \mathrm{L})$ was dropped onto a silicon wafer and dried. The parylene- $\mathrm{N}$ films were deposited with a thickness of $100 \mathrm{~nm}$. A mixture of HRP $(10 \mu \mathrm{g} / \mathrm{mL})$ in a $1: 1(\mathrm{v} / \mathrm{v})$ mixture of PBS and hydrogen peroxide was dropped onto the Amplex Red spots. After drying the HRP and $\mathrm{H}_{2} \mathrm{O}_{2}$ mixture, the red fluorescence was detected using fluorescence microscopy (LS55, PerkinElmer, Wellesley, MA, USA) with an excitation wavelength of $510-550 \mathrm{~nm}$ and an emission filter of $590 \mathrm{~nm}$ at an exposure time of 1-2 s. The morphology and structure of the parylene matrix chip were analyzed using fluorescence imaging. Fluorescence images were taken after fluorescein was dissolved in $\mathrm{NaOH}(0.1 \mathrm{M})$ and dispensed on the parylene matrix chip.

\section{Derivatization of vitamin $D_{3}$ for MALDI-TOF mass spectrometry}

BA derivatization was performed by adding a vitamin $\mathrm{D}_{3}$ solution to ethanol. BA solution $(0.05 \mathrm{mg} / \mathrm{mL})$ was prepared using a mixture of acetonitrile and water (1:1 $(\mathrm{v} / \mathrm{v}))$. The mixture was vortexed for $10 \mathrm{~s}$ and allowed to react for $30 \mathrm{~min}$ at room temperature (Wu et al. 2009). For acid-induced degradation, vitamin $\mathrm{D}_{3}(0.45 \mathrm{pmol} / \mu \mathrm{L})$ was added to a mixture of ethanol and $\mathrm{HCl}(100: 1(\mathrm{v} / \mathrm{v}))$ and refluxed for $5 \mathrm{~h}$ at $70{ }^{\circ} \mathrm{C}$ (Mahmoodani et al. 2017). For PTAD derivatization, vitamin $\mathrm{D}_{3}(0.45 \mathrm{pmol} / \mu \mathrm{L})$ was added to PTAD solution $(0.5 \mathrm{mg} / \mathrm{mL})$ in acetonitrile and reacted at room temperature for $4 \mathrm{~h}$ (Ding et al. 2010).

\section{MALDI-TOF mass spectrometry analysis of vitamin $D_{3}$}

Mass spectrometric analysis was performed using a Microflex MALDI TOF mass spectrometer (Bruker Daltonics, Billerica, MA, USA) in the reflective positive mode with the first and second ion source voltages of 20 and $18 \mathrm{kV}$, respectively. A nitrogen laser with a wavelength of $337 \mathrm{~nm}$ was equipped with a trigger frequency of $60 \mathrm{~Hz}$. The power of the irradiated laser was adjusted to $40 \%$ of the maximum energy of $59.7 \mu \mathrm{J}$. All mass spectra were obtained by integrating the data of 500 laser pulses for each sample spot. For MALDI-TOF mass spectrometric analysis, the derivatized products $(0.7 \mu \mathrm{L})$ were dispensed at five different spots on the surface of the parylene matrix chip. The mean values of signal intensities from five different spots at the same concentration of vitamin D metabolites were used to calculate the signal. The measured intensities for each concentration were plotted as graphs and linearly approximated using the least-squares method. The limit of detection was calculated to be three times the noise level. The reproducibility of MALDI-TOF mass spectrometry was verified by the inter-spot and intra-spot analyses of $25(\mathrm{OH}) \mathrm{D}_{3}$ at $0.45 \mathrm{pmol} / \mu \mathrm{L}$. Inter-spot analysis was carried out at five different sample spots of $25(\mathrm{OH}) \mathrm{D}_{3}$ at a concentration of $0.45 \mathrm{pmol} / \mu \mathrm{L}$, and the measurement was taken by the partial random walk function. Intra-spot analysis was also carried out in same sample spot of $25(\mathrm{OH}) \mathrm{D}_{3}$ at a concentration of $0.45 \mathrm{pmol} / \mu \mathrm{L}$ through five rounds of repeated measurements by the partial random walk function. For quantitative analysis by MALDI-TOF mass spectrometry, $25(\mathrm{OH}) \mathrm{D}_{3}$ solutions were prepared at different concentrations in ethanol. To demonstrate the feasibility of real sample analysis, $180 \mu \mathrm{L}$ of human serum was spiked with $20 \mu \mathrm{L}$ of $25(\mathrm{OH}) \mathrm{D}_{3}$ at different concentrations in ethanol. For sample preparation, acetonitrile $(200 \mu \mathrm{L})$ was added to vitamin-spiked serum $(200 \mu \mathrm{L})$ and vortexed for $15 \mathrm{~s}$. Liquid-liquid extraction (LLE) was performed by adding $1 \mathrm{~mL}$ of hexane and vortexing for $15 \mathrm{~s}$, followed by centrifugation at $14,000 \mathrm{rpm}$ for $15 \mathrm{~min}$ at $4{ }^{\circ} \mathrm{C}$ (Park et al. 2020a). The supernatant of the mixture $(800 \mu \mathrm{L})$ was transferred to a fresh EP tube, and the solvent was evaporated using $\mathrm{N}_{2}$ gas $\left(45^{\circ} \mathrm{C}\right)$. The evaporated sample was resuspended in a mixture of methanol and water $(50 \mu \mathrm{L})$ and vortexed for $30 \mathrm{~s}$. After centrifugation at 14,000 rpm for $10 \mathrm{~min}$, the supernatant was transferred to a fresh EP tube for MALDI-TOF MS analysis.

\section{Statistical analysis}

As a reference method, electrochemiluminescence immunoassay (ECLIA) was employed to analyze the $25(\mathrm{OH}) \mathrm{D}_{3}$ solutions in ethanol at different concentrations using the Elecsys Vitamin D analysis kit from Roche (Mannheim, Germany), and the ECLIA measurement was taken at Seoul Clinical Laboratories (SCL, Seoul, Korea) (Kim et al. 2020). Bland-Altman plot and Passing-Bablok regression were used (MedCalc software, version 18.6) to confirm the coincidence of the two analysis methods used for $25(\mathrm{OH}) \mathrm{D}_{3}$ : (1) MALDI-TOF mass spectrometry based on the parylene matrix chip and (2) ECLIA.

\section{Results and discussion}

Properties of the parylene matrix chip

MALDI-TOF MS has been commonly utilized for the detection of biomolecules through mild ionization using 
organic matrix molecules (Fig. 1a). Conventional organic matrices for MALDI-TOF mass spectrometry have been reported to produce unreproducible mass peaks in the low $\mathrm{m} / \mathrm{z}$ range, which interfere with the detection of small molecules, especially those with a molecular weight of less than $1 \mathrm{kDa}$. When the conventional organic matrix (CHCA) was measured repeatedly at the same spot, unreproducible mass peaks from fragmented organic matrix molecules were observed in the low $\mathrm{m} / \mathrm{z}$ range, as shown in Fig. 1b. The blue arrows of the mass peaks displayed different intensities, and the red arrows of the mass peaks sometimes disappeared in the mass spectra. Recently, MALDI-TOF mass spectrometry based on the parylene matrix chip has been developed for the quantitative analysis of small molecules, which could remove the interfering mass peaks from the fragmented organic matrices in the low $\mathrm{m} / z$ range of less than 500 (Kim et al. 2017b, 2014a, 2014b; Park et al. 2017). As previously reported (Kim et al. 2017b, 2014a, 2014b), a parylene matrix chip was produced via the deposition of a parylene film on a dried organic matrix, such as CHCA and DHB. Usually, the direct exposure of a dried matrix spot to a UV laser produces unreproducible mass peaks from fractions of matrix molecules. When a parylene film with a thickness of less than $50 \mathrm{~nm}$ was deposited on the dried matrix spot, the mass peaks from matrix molecules were observed to disappear upon absorption of the parylene film, as shown in Fig. 1c. Through addition of the sample, only the mass peaks from analytes were observed in the sample without any mass peaks from matrix molecules. The function of the parylene film was previously proposed to result from the mixing of the analyte between the dried matrix spot and the liquid sample within the porous parylene film. The porosity of the parylene film with a thickness of less than $50 \mathrm{~nm}$, as well as the transfer of small ions through the porous parylene film, was demonstrated using cyclic voltammetry on a gold electrode, as shown in Additional file 1: Fig. S1 (Kim et al. 2014a). However, the mixing zone for analytes and matrix molecules has not been reported to be directly observed within the porous parylene film. To prove the existence of a mixing zone within the porous parylene film, an analog structure of the parylene matrix chip was developed, as shown in Fig. 2a. The fluorescence probe called Amplex Red (transparent with no fluorescence) was dried on the target plate prior to the deposition of the parylene film with a thickness of $50 \mathrm{~nm}$. The fluorescence probe is oxidized into resorufin (with fluorescence, $\lambda_{\mathrm{em}}=590 \mathrm{~nm}$ ) by HRP mixed with hydrogen peroxide $\left(\mathrm{H}_{2} \mathrm{O}_{2}\right)$, as shown in Fig. 2b. Red fluorescence of resorufin was observed in the Amplex Red chip without parylene- $\mathrm{N}$ film deposition, and the morphology was the same as that of the nonhomogeneous dried $\mathrm{HRP} / \mathrm{H}_{2} \mathrm{O}_{2}$ mixture crystal (Fig. 2c).
The parylene- $\mathrm{N}$ film was deposited on the Amplex Red spot after the $\mathrm{HRP} / \mathrm{H}_{2} \mathrm{O}_{2}$ mixture solution was dried, and red fluorescence was also observed at the cross section of the parylene film. This result suggests that the $\mathrm{HRP} / \mathrm{H}_{2} \mathrm{O}_{2}$ solution was mixed with the dried Amplex Red reagent through the parylene- $\mathrm{N}$ film. Therefore, a sample-matrix mixing zone of the parylene matrix chip was formed below the surface of the parylene-N film.

The inhomogeneous crystal formation of the matrixanalyte mixture caused difficulty in the quantitative analysis (Cohen and Gusev 2002). Fluorescence was detected by dispensing fluorescein dissolved in sodium hydroxide $(0.1 \mathrm{M})$ on the bare plate, organic matrix, and parylene matrix chip. From the fluorescence image, as shown in Fig. $2 \mathrm{~d}$, the matrix in the parylene matrix chip showed a homogeneous distribution compared with the bare plate (stainless steel plate) and CHCA organic matrix spot. Accordingly, organic matrix molecules were considered to be homogeneously distributed on the surface of the parylene matrix chip, where the analyte molecules could be ionized with enhanced reproducibility. Homogeneous surfaces enhance the reproducibility of analytes in MALDI-TOF mass spectrometry (Ha et al. 2011; O’Rourke et al. 2018; Szaéjli et al. 2008).

\section{Analysis of vitamin D}

In this section, vitamin D metabolites were detected after chemical derivatization using MALDI-TOF mass spectrometry based on parylene matrix chip. The detection of vitamin D metabolites has been difficult due to their hydrophobic characteristics, lack of polar functional groups, and low concentrations in plasma. Among various vitamin $\mathrm{D}$ metabolites, $25(\mathrm{OH}) \mathrm{D}_{3}$ has been selected as a biomarker for various diseases (Ding et al. 2010; Zerwekh 2008).

For effective detection, derivatization methods of vitamin D have been studied, and BA was selectively reacted to the hydroxyl group of the $25(\mathrm{OH}) \mathrm{D}_{3}$ as well as vitamin $\mathrm{D}_{3}$ by nucleophilic addition to form a hemiacetal salt with a charge labeling effect, as shown in Fig. 3a. The BAderivatized $25(\mathrm{OH}) \mathrm{D}_{3}$ and vitamin $\mathrm{D}_{3}$ could be detected using the conventional organic matrix called $\mathrm{CHCA}$, and the mass peaks from the fragmented matrix molecules could be effectively removed using MALDI-TOF mass spectrometry based on the parylene matrix chip, as shown in Fig. 3b. When the mixture of BA-derivatized $25(\mathrm{OH}) \mathrm{D}_{3}$ and $\mathrm{BA}$-derivatized vitamin $\mathrm{D}_{3}$ was analyzed using the parylene matrix chip, both target analytes could be simultaneously detected without the mass peaks from the fragmented matrix molecules.

Another chemical derivatization method was employed to prepare isotachysterol via the acid-catalyzed isomerization of vitamin D in ethanol (Agarwal 1990; Jin et al. 

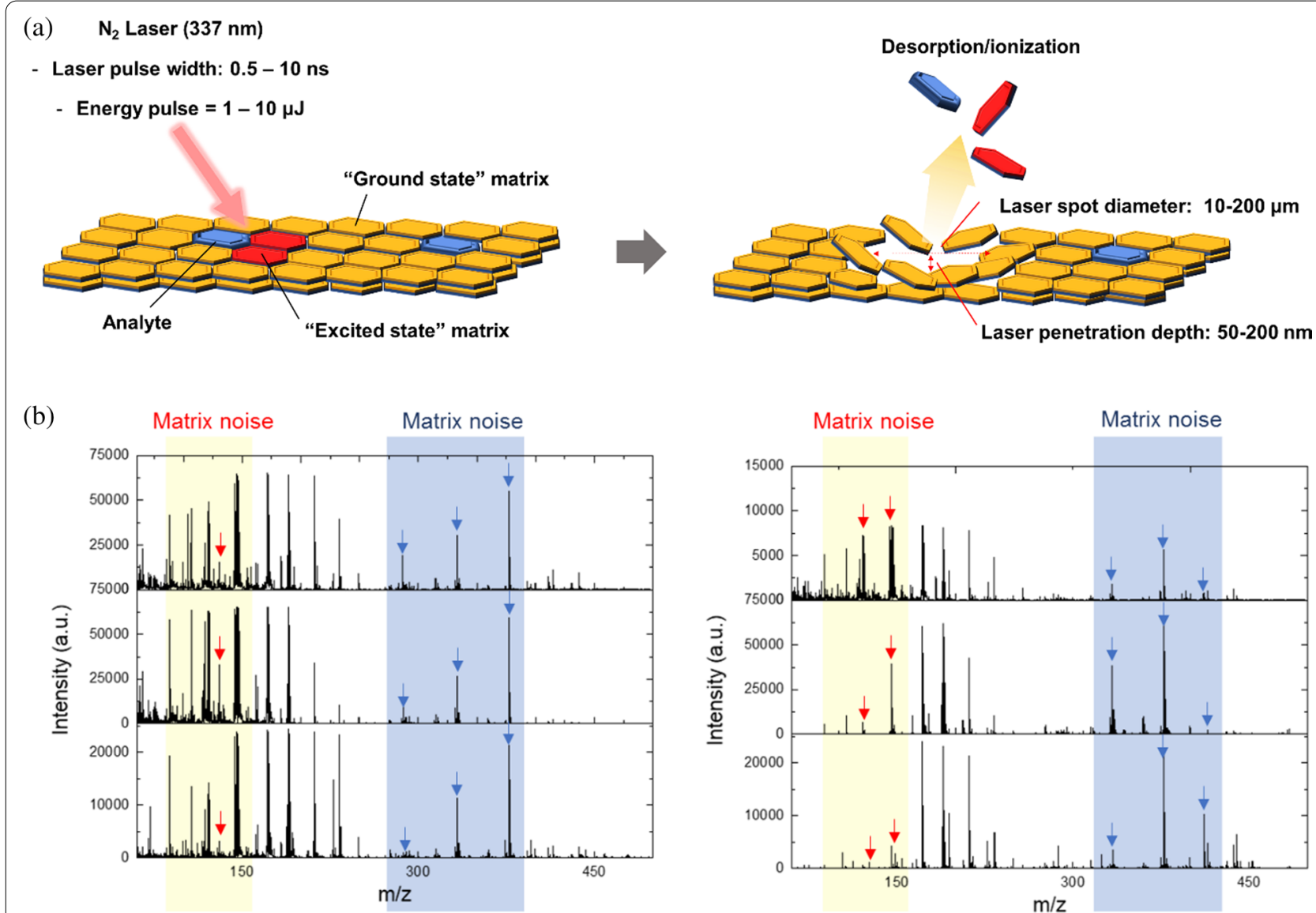

(b)

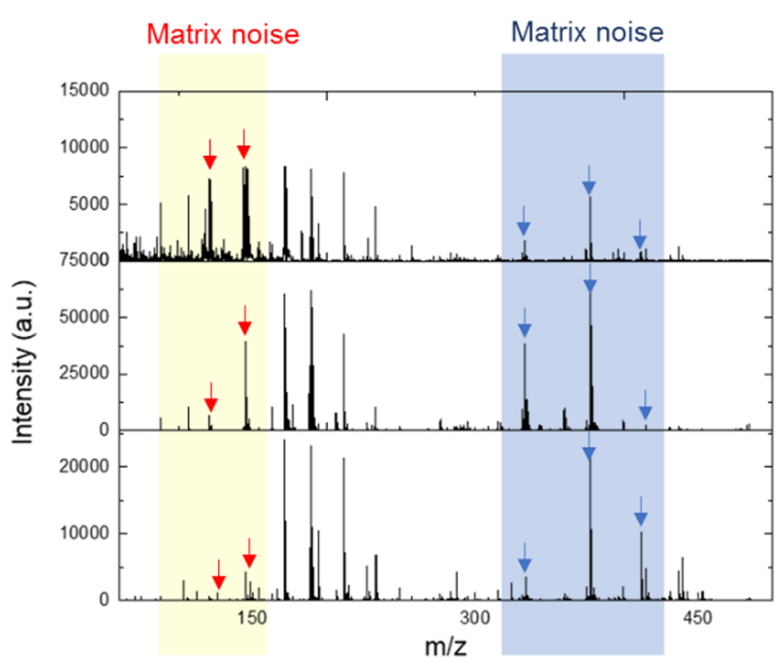

(c)
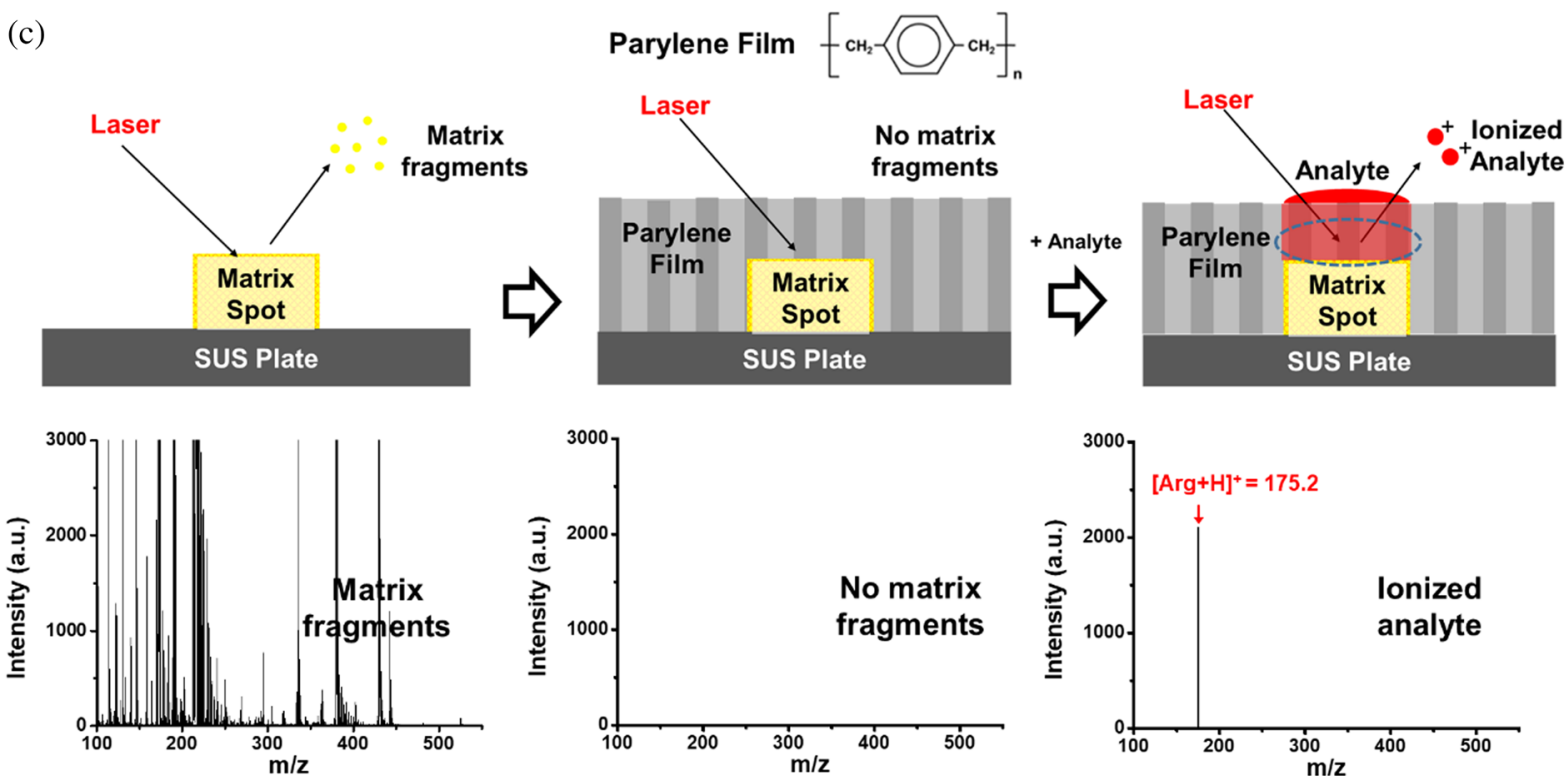

Fig. 1 Vitamin derivatization using betaine aldehyde and preparation of the parylene matrix chip. a Principle of MALDI-TOF mass spectrometry. $\mathbf{b}$ Mass spectra of the organic matrix (CHCA) from repeated measurements. $\mathbf{c}$ Preparation scheme of parylene matrix chip and mass spectra of each preparation process 
(a)

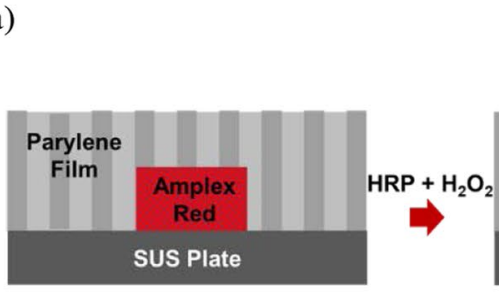

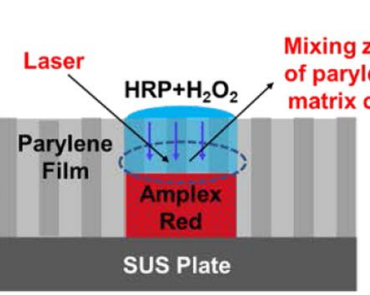

\section{cf. Parylene matrix chip}

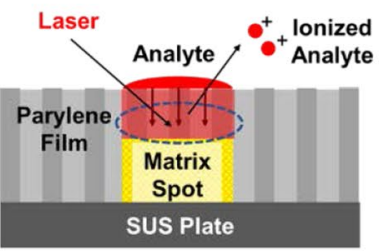

(b)<smiles>CC(=O)n1c2ccc(O)cc2oc2cc(O)ccc2n1C(C)=O</smiles>

(c)

Bright image
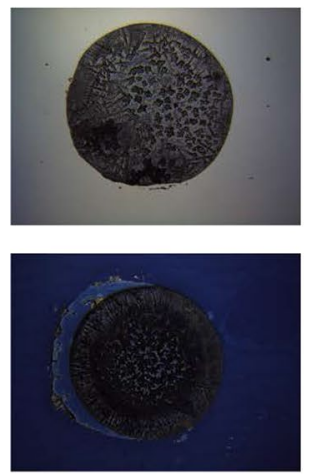

(d)
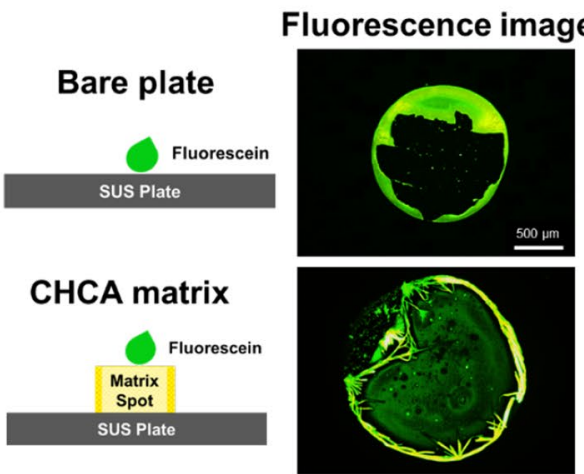

Parylene matrix chip
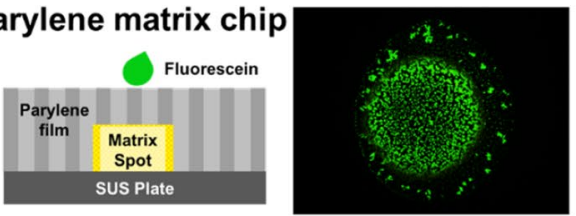
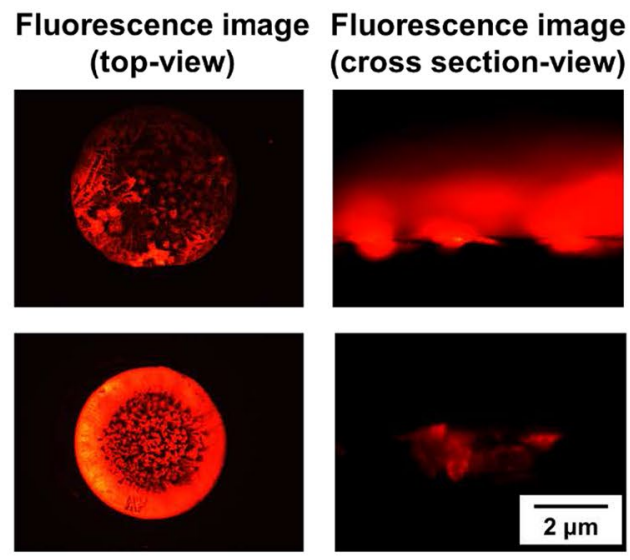

No parylene film

With parylene film $(\sim 100 \mathrm{~nm})$

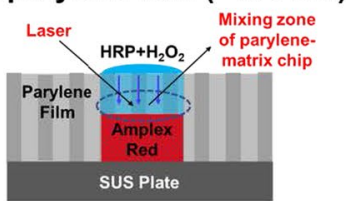

Line graph
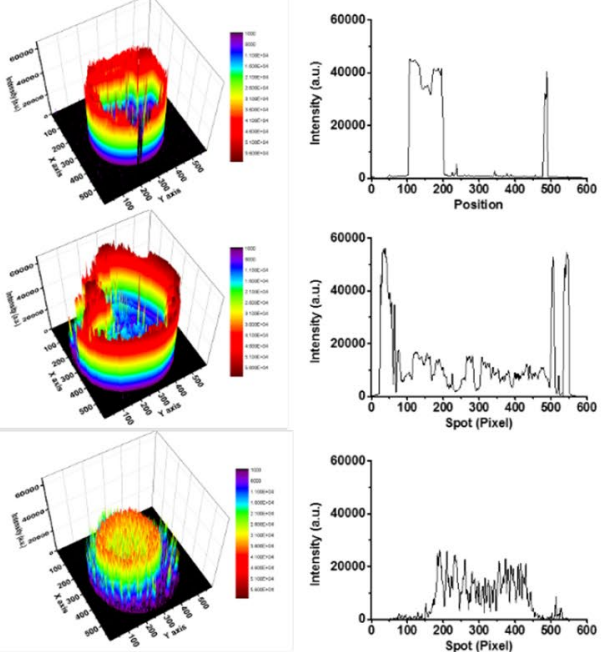

Fig. 2 Characterization of the parylene matrix chip. a Scheme of the mixing zone of parylene-N film. b Amplex Red assay reaction with $\mathrm{H}_{2} \mathrm{O}_{2}$ and peroxidase. $\mathbf{c}$ Fluorescence image of Amplex Red assay with or without the parylene-N film. $\mathbf{d}$ Fluorescence images of bare plate, $\mathrm{CHCA}$ matrix, and parylene matrix chip 
(a)

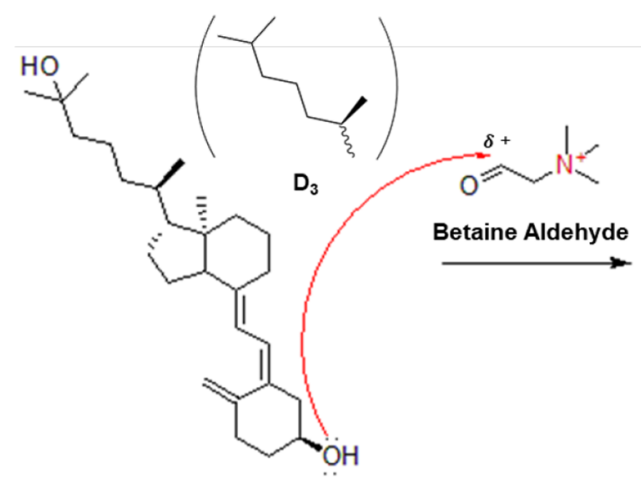

$25(\mathrm{OH}) \mathrm{D}_{3}$

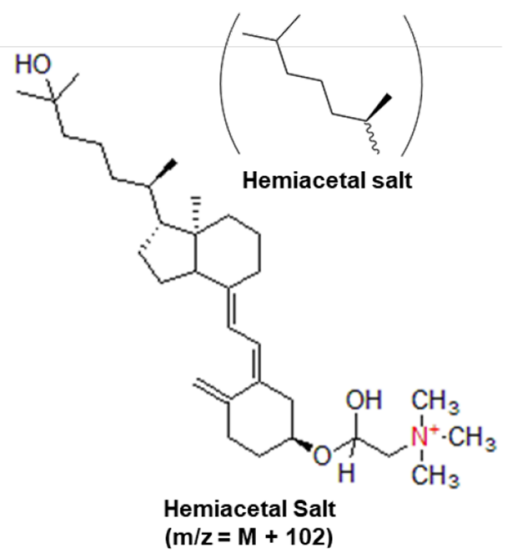

(b)
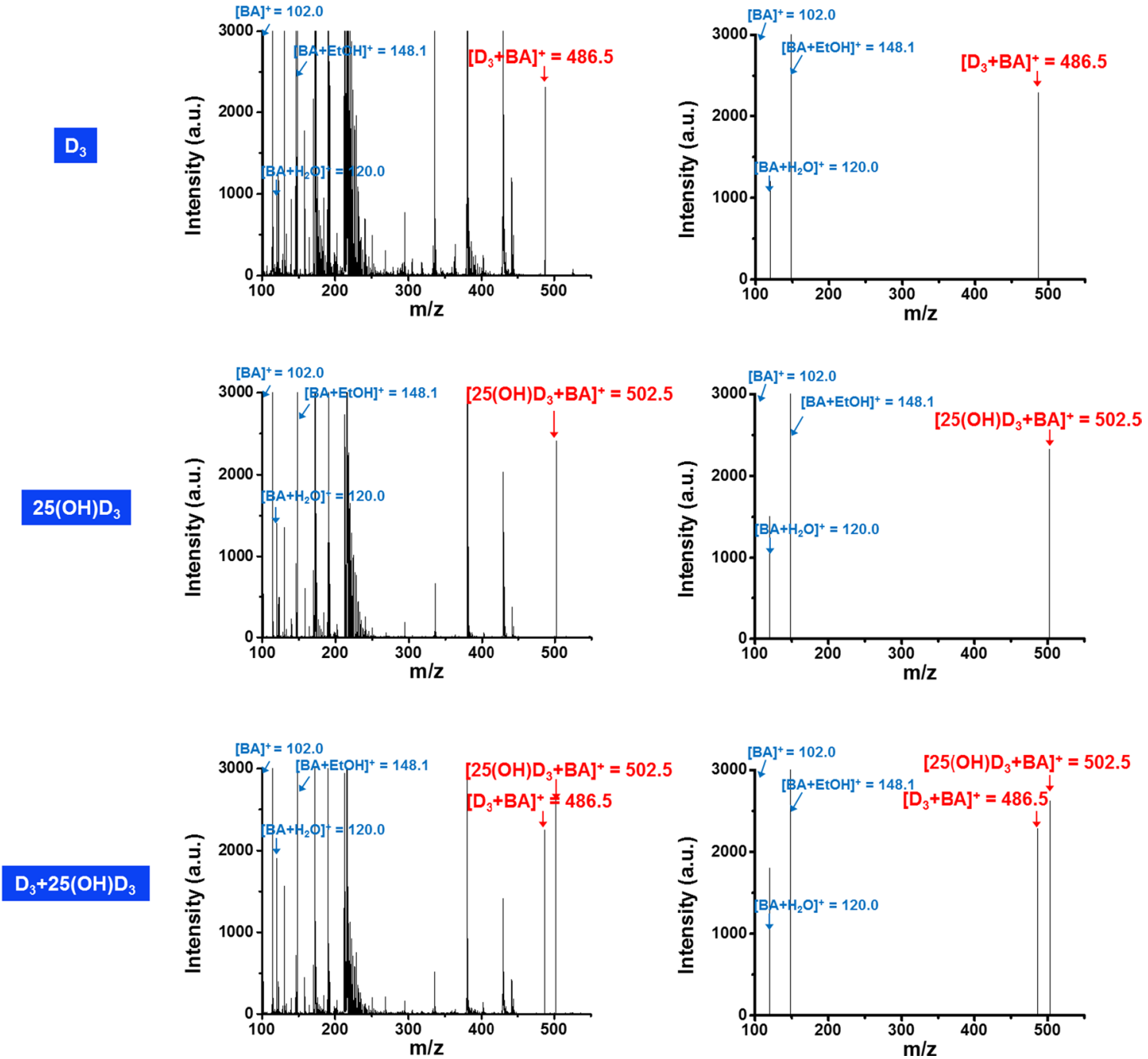

Fig. 3 Chemical derivatization of vitamin D a Reaction diagram between the betaine aldehyde cation and the hydroxyl group of an alcohol in vitamin D. b Comparison of CHCA matrix and parylene matrix chip for the analysis of vitamin mixtures after BA derivatization. c Reaction diagram of the acid-induced degradation and the mass spectrum of the product of derivatization. $\mathbf{d}$ Reaction diagram of PTAD and vitamin D and the mass spectrum of the product of PTAD derivatization 
(c)
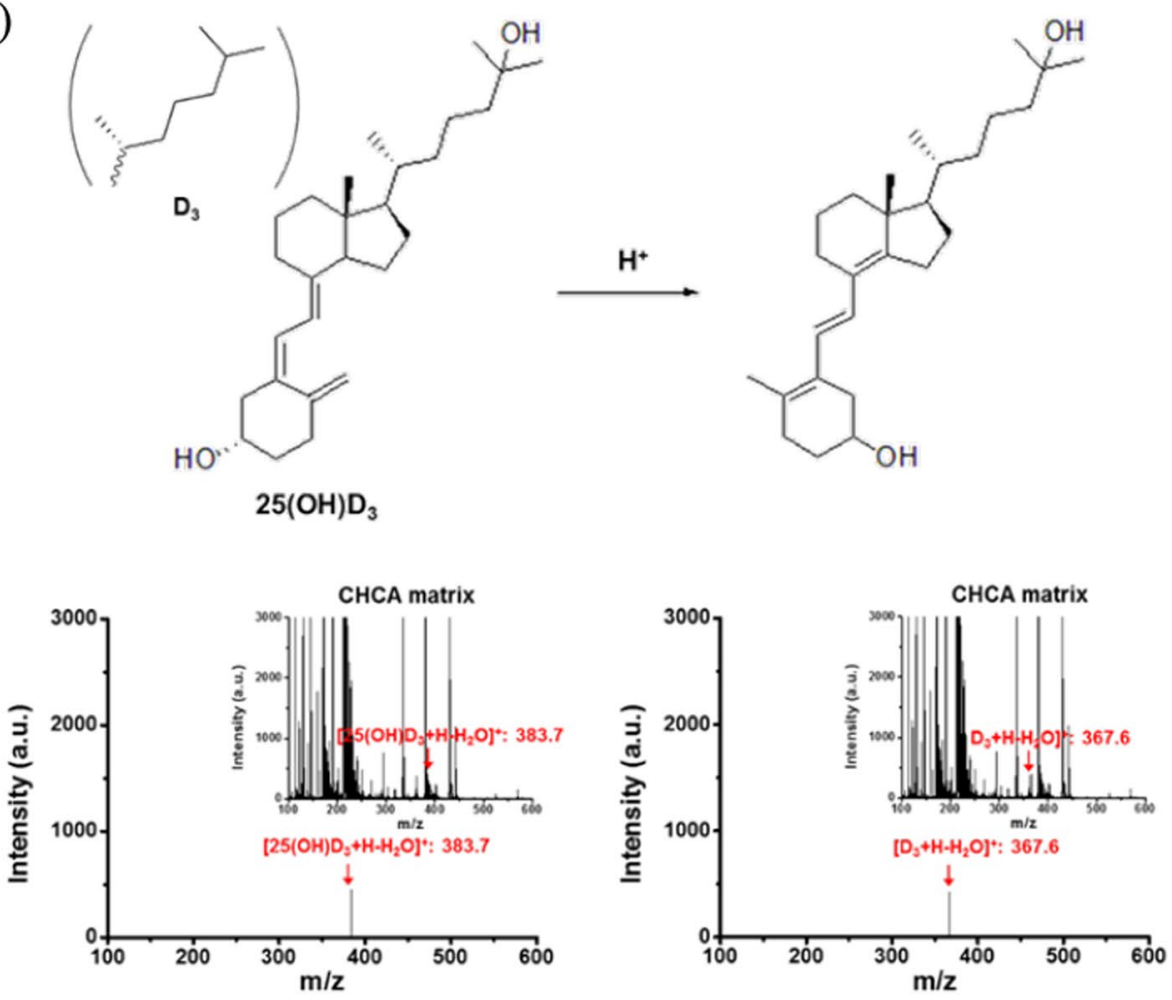

(d)
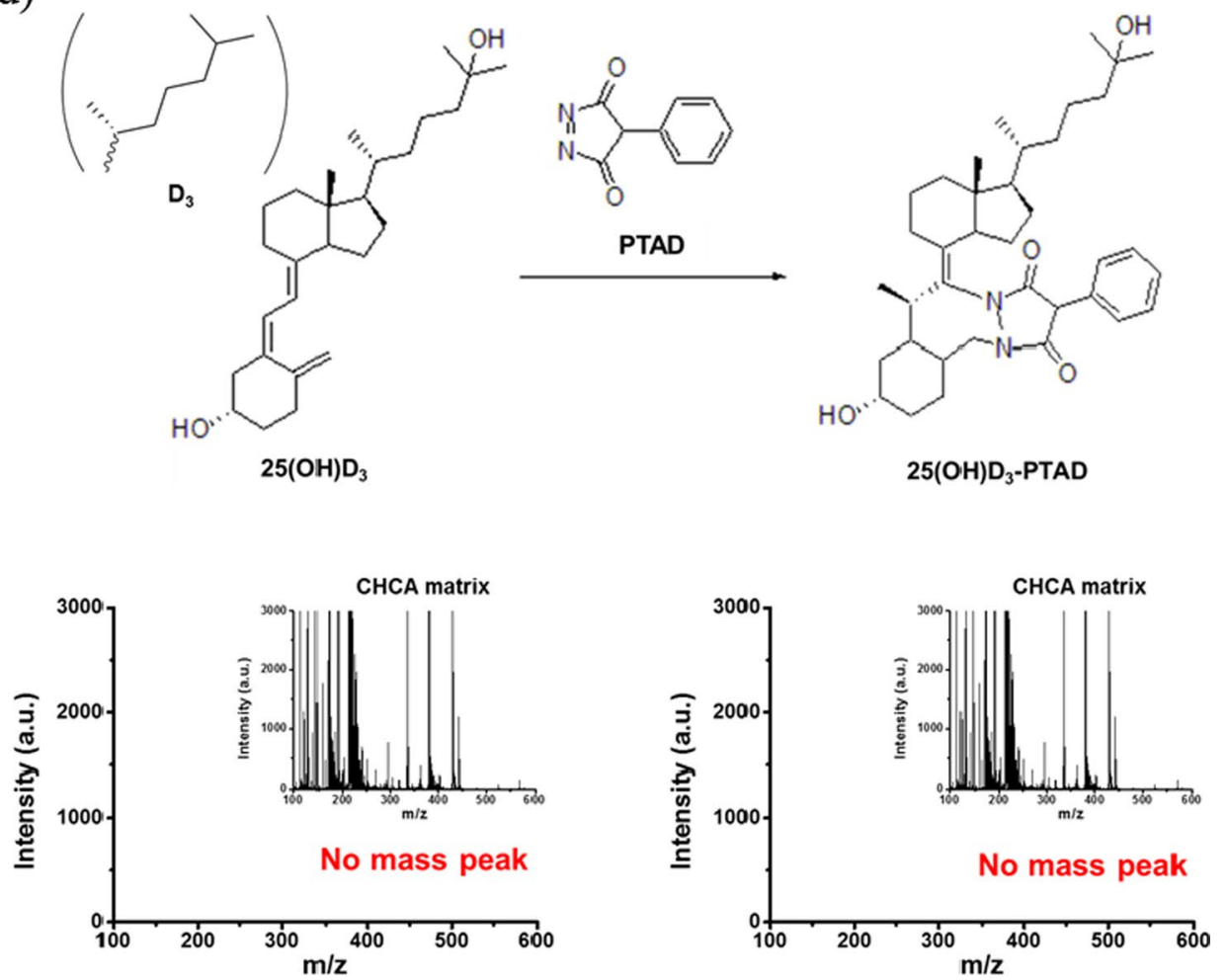

Fig. 3 continued 
2004; Seamark et al. 1980). The dehydrated form of isotachysterol was detected under MALDI-TOF mass conditions as degraded ion peaks, as shown in Fig. 3c (Mahmoodani et al. 2017). The derivatized form of $25(\mathrm{OH}) \mathrm{D}_{3}$ was $\left[25(\mathrm{OH}) \mathrm{D}_{3}+\mathrm{H}-\mathrm{H}_{2} \mathrm{O}\right]^{+} \quad(\mathrm{m} / z=383.7)$, and the derivatized form of $\mathrm{D}_{3}$ was $\left[\mathrm{D}_{3}+\mathrm{H}-\mathrm{H}_{2} \mathrm{O}\right]^{+}$ $(\mathrm{m} / z=367.6)$ based on conventional MALDI-TOF mass spectrometry using an organic matrix ( $\mathrm{CHCA}$ ) as well as a parylene matrix chip.

The Diels-Alder reaction of vitamin D with 4-phenyl-1,2,4-triazoline-3,5-dione (PTAD), including atoms with high proton affinity (such as oxygen and nitrogen), was also employed (Aronov et al. 2008; Ding et al. 2010; Higashi et al. 2001, 2008). However, PTAD was not effective for the modification of vitamin D molecules owing to the low solubility of PTAD in protic solvents, long reaction time, and difficult reaction with a low sample volume. The derivatized product of vitamin D molecules was observed to have a chemical structure without any charged functional groups. Further, no mass peaks were observed based on MALDI-TOF mass spectrometry using organic matrix molecules or a parylene matrix chip, as shown in Fig. 3d. Owing to these results, the vitamin D molecules were analyzed after derivatization of BA, and MALDI-TOF mass spectrometry based on the parylene matrix chip was used for effective detection at high $\mathrm{S} / \mathrm{N}$ ratios without mass peaks from fragmented organic matrix molecules.

Quantitative analysis of vitamin D molecules was performed using a parylene matrix chip. As previously mentioned, the inhomogeneous crystal formation of the matrix-analyte mixture caused difficulty in the quantitative analysis, and the parylene matrix chip was demonstrated to be useful for quantitative analysis using MALDI-TOF mass spectrometry. The feasibility of the quantitative analysis of vitamin D molecules was investigated by estimating the reproducibility of the inter-spot and intra-spot measurements. To measure inter-spot reproducibility, five sample spots were independently prepared using BA-derivatized vitamin D molecules on the parylene matrix chip, and the MALDI-TOF mass spectra were obtained at different spots, as shown in Additional file 1: Fig. S2(a) and Fig. S2(b). Based on the analysis of the mass spectra, the inter-spot reproducibility was $4.2 \%$ for $25(\mathrm{OH}) \mathrm{D}_{3}(0.45 \mathrm{pmol} / \mu \mathrm{L})$ as shown in Fig. $4 \mathrm{a}$, and $3.1 \%$ for vitamin $\mathrm{D}_{3}(0.45 \mathrm{pmol} / \mu \mathrm{L})$, as shown in Fig. 4b. To estimate intra-spot reproducibility, a sample spot was prepared using BA-derivatized vitamin D molecules on the parylene matrix chip, and the MALDITOF mass spectra were obtained at different positions, as shown in Additional file 1: Fig. S2c, d. Based on the analysis of the mass spectra, the intra-spot reproducibility was $3.0 \%$ for $25(\mathrm{OH}) \mathrm{D}_{3}(0.45 \mathrm{pmol} / \mu \mathrm{L})$ as shown in
Fig. $4 \mathrm{c}$ and $2.6 \%$ for vitamin $\mathrm{D}_{3}(0.45 \mathrm{pmol} / \mu \mathrm{L})$, as shown in Fig. 4d. Therefore, the analysis of BA-derivatized vitamin $\mathrm{D}$ molecules could be conducted with high interand intra-spot reproducibility using MALDI-TOF mass spectrometry based on a parylene matrix chip.

For the quantitative analysis of vitamin $\mathrm{D}$ molecules, standard samples of BA-derivatized $25(\mathrm{OH}) \mathrm{D}_{3}$ and vitamin $\mathrm{D}_{3}$ in ethanol were prepared in the concentration range of $0.0056-1.35 \mathrm{pmol} / \mu \mathrm{L}$. Further, mass spectra with the targeted mass peak of $25(\mathrm{OH}) \mathrm{D}_{3}([25(\mathrm{OH})$ $\left.\mathrm{D}_{3}+\mathrm{BA}\right]^{+}=502.5$ and vitamin $\mathrm{D}_{3}\left(\left[\mathrm{D}_{3}+\mathrm{BA}\right]^{+}=486.5\right.$ were obtained using MALDI-TOF mass spectrometry based on the parylene matrix chip, as shown in Fig. 5a and Additional file 1: Fig. S3(a). The standard curves for derivatized $25(\mathrm{OH}) \mathrm{D}_{3}$ (with a linearity factor of 0.994 ) and vitamin $\mathrm{D}_{3}$ (with a linearity factor of 0.999) were plotted, as shown in Fig. 5b, and the limit of detection (LOD) was estimated to be $0.0056 \mathrm{pmol} / \mu \mathrm{L}$ for $25(\mathrm{OH}) \mathrm{D}_{3}$ and $0.0056 \mathrm{pmol} / \mu \mathrm{L}$ for vitamin $\mathrm{D}_{3}$ with a cut-off value of $0.026 \mathrm{pmol} / \mu \mathrm{L}$. The LOD was marked with an asterisk (*), and the cut-off value was marked with a double asterisk $(* *)$ in the standard curves of $25(\mathrm{OH}) \mathrm{D}_{3}$ and vitamin $\mathrm{D}_{3}$. The standard samples of $25(\mathrm{OH}) \mathrm{D}_{3}$ and vitamin $\mathrm{D}_{3}$ in serum were prepared by spiking an amount ranging from 0.0056 to $1.35 \mathrm{pmol} / \mu \mathrm{L}$. Further, the vitamin $\mathrm{D}$ molecules were isolated from serum by liquid-liquid extraction with acetonitrile and hexane prior to derivatization with $\mathrm{BA}$. The mass spectra with the targeted mass peak of $25(\mathrm{OH}) \mathrm{D}_{3}\left(\left[25(\mathrm{OH}) \mathrm{D}_{3}+\mathrm{BA}\right]^{+}=502.5\right.$, and vitamin $\mathrm{D}_{3}\left(\left[\mathrm{D}_{3}+\mathrm{BA}\right]^{+}=486.5\right.$ were obtained using MALDITOF mass spectrometry based on the parylene matrix chip, as shown in Fig. 5c and Additional file 1: Fig. S3(b). The standard curves for derived $25(\mathrm{OH}) \mathrm{D}_{3}$ (with a linearity factor of 0.994) and vitamin $\mathrm{D}_{3}$ (with a linearity factor of 0.999) were plotted, as shown in Fig. 5d, and the limit of detection (LOD) was estimated to be $0.0056 \mathrm{pmol} / \mu \mathrm{L}$ for $25(\mathrm{OH}) \mathrm{D}_{3}$ and $0.0056 \mathrm{pmol} / \mu \mathrm{L}$ for vitamin $\mathrm{D}_{3}$, with a cut-off value of $0.026 \mathrm{pmol} / \mu \mathrm{L}$. These results indicate that $25(\mathrm{OH}) \mathrm{D}_{3}$ and vitamin $\mathrm{D}_{3}$ in ethanol and serum could be quantitatively determined with high linearity using MALDI-TOF mass spectrometry based on a parylene matrix chip.

The standard techniques for the quantification of $25(\mathrm{OH}) \mathrm{D}_{3}$ in blood include enzyme-linked immunosorbent assay (ELISA) and liquid chromatographytandem mass spectrometry (LC-MS/MS) (Hollis and Napoli 1985; Jenkinson et al. 2016; Kim et al. 2017a). In this study, Elecsys Vitamin D analysis kit from Roche (Mannheim, Germany) was used as a reference and its quantification results for $25(\mathrm{OH}) \mathrm{D}_{3}$ were compared to those from MALDI-TOF mass spectrometry based on a parylene matrix chip. The quantification results from MALDI-TOF mass spectrometry and ECLIA are plotted 

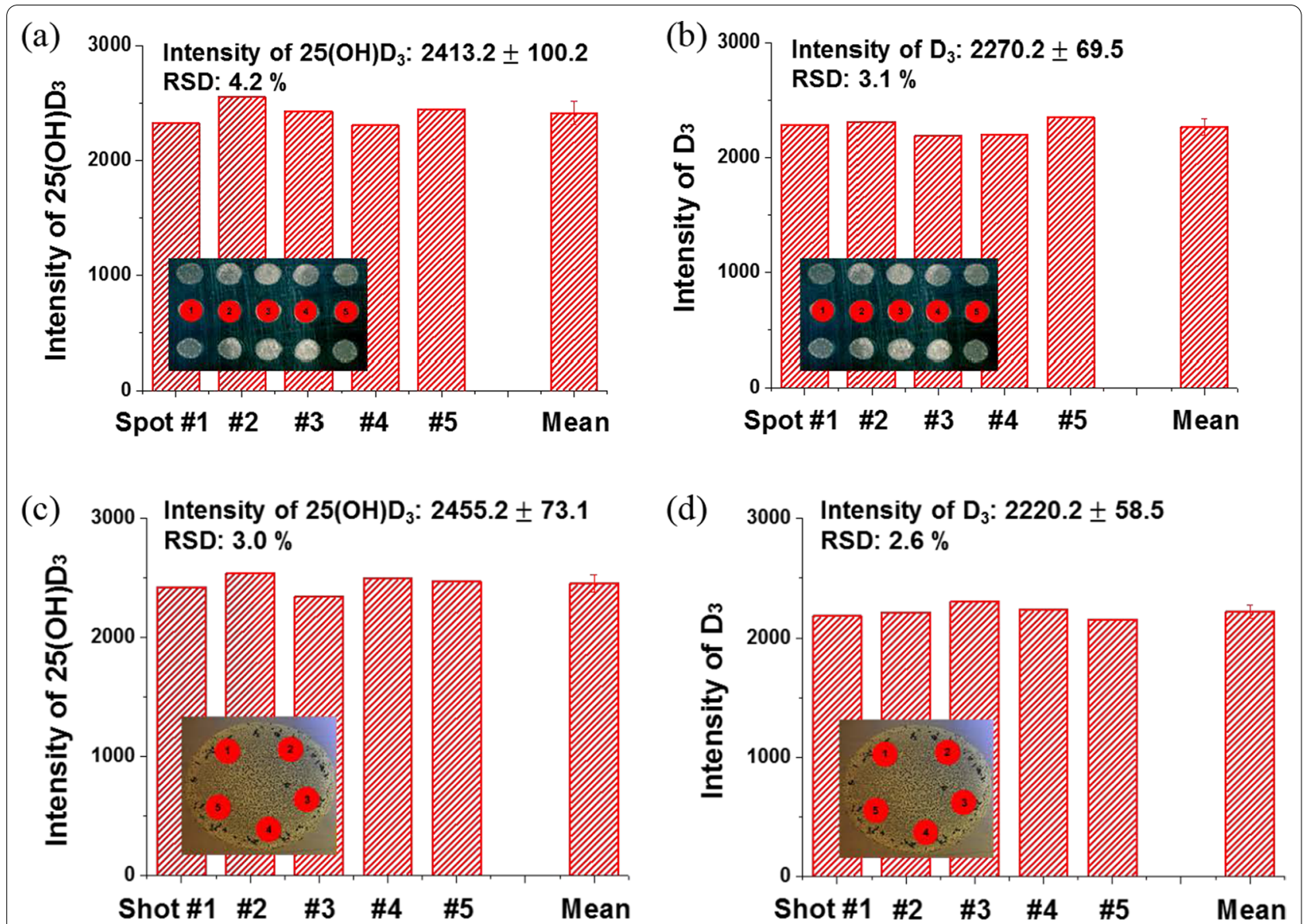

Fig. 4 Reproducibility of the parylene matrix chip. a Spot-to-spot reproducibility of $25(\mathrm{OH}) \mathrm{D}_{3}$. b Spot-to-spot reproducibility of $\mathrm{D}_{3}$. c Shot-to-shot reproducibility of $25(\mathrm{OH}) \mathrm{D}_{3}$. d Shot-to-shot reproducibility of $\mathrm{D}_{3}$

in the same graph in Fig. 6a, and these standard curves show a high linearity for both methods. To estimate the statistical co-incidence of the two methods for vitamin $\mathrm{D}_{3}$, the Bland-Altman plot and Passing-Bablok regression were conducted using MedCalc software (version 18.6). The Bland-Altman test revealed that a signal difference was distributed at a confidence level of $95 \%( \pm$ $1.96 \sigma$ ), as shown in Fig. 6b. This result demonstrated that the two methods were highly correlated and provided the same analysis result for the detection of $25(\mathrm{OH}) \mathrm{D}_{3}$. Passing-Bablok regression revealed that the analysis data from both methods were distributed at a confidence level of $95 \%$, with a Spearman correlation coefficient $(\rho)$ of $1.000(P<0.0001)$, as shown in Fig. 6c. These results show that the two different methods were statistically highly coincident. This result also showed that the two methods were highly correlated and provided the same analysis results for the detection of $25(\mathrm{OH}) \mathrm{D}_{3}$.
The applicability of MALDI-TOF mass spectroscopy based on a parylene matrix chip for the quantification of vitamin $\mathrm{D}_{3}$ in real samples was presented using commercially available energy drinks and vitamin $D_{3}$ tablets as real samples. The energy drink mainly contained vitamin $\mathrm{C}$, vitamin $\mathrm{D}_{3}$, zinc, biotin, and sodium, according to the manufacturer's label. An energy drink was added to the BA solution for BA derivatization and then loaded onto the parylene matrix chip for mass analysis. As shown in Fig. $7 \mathrm{a}$, both vitamin $\mathrm{C}$ and vitamin $\mathrm{D}_{3}$ reacted with BA. The mass peak from vitamin $C$ was observed to have a higher intensity than that from vitamin $D_{3}$, indicating that the relative amount of vitamin $\mathrm{C}$ was markedly higher than that of vitamin $D_{3}$, as indicated on the manufacturer's label (vitamin C: $13.0 \mathrm{pmol} / \mu \mathrm{L}$, vitamin $\mathrm{D}_{3}: 0.65 \mathrm{pmol} / \mu \mathrm{L}$ ). Vitamin $\mathrm{D}_{3}$ tablet as a dietary supplement was also analyzed using the same method, and the mass peak from $\mathrm{BA}$-adducted vitamin $\mathrm{D}_{3}$ was measured 


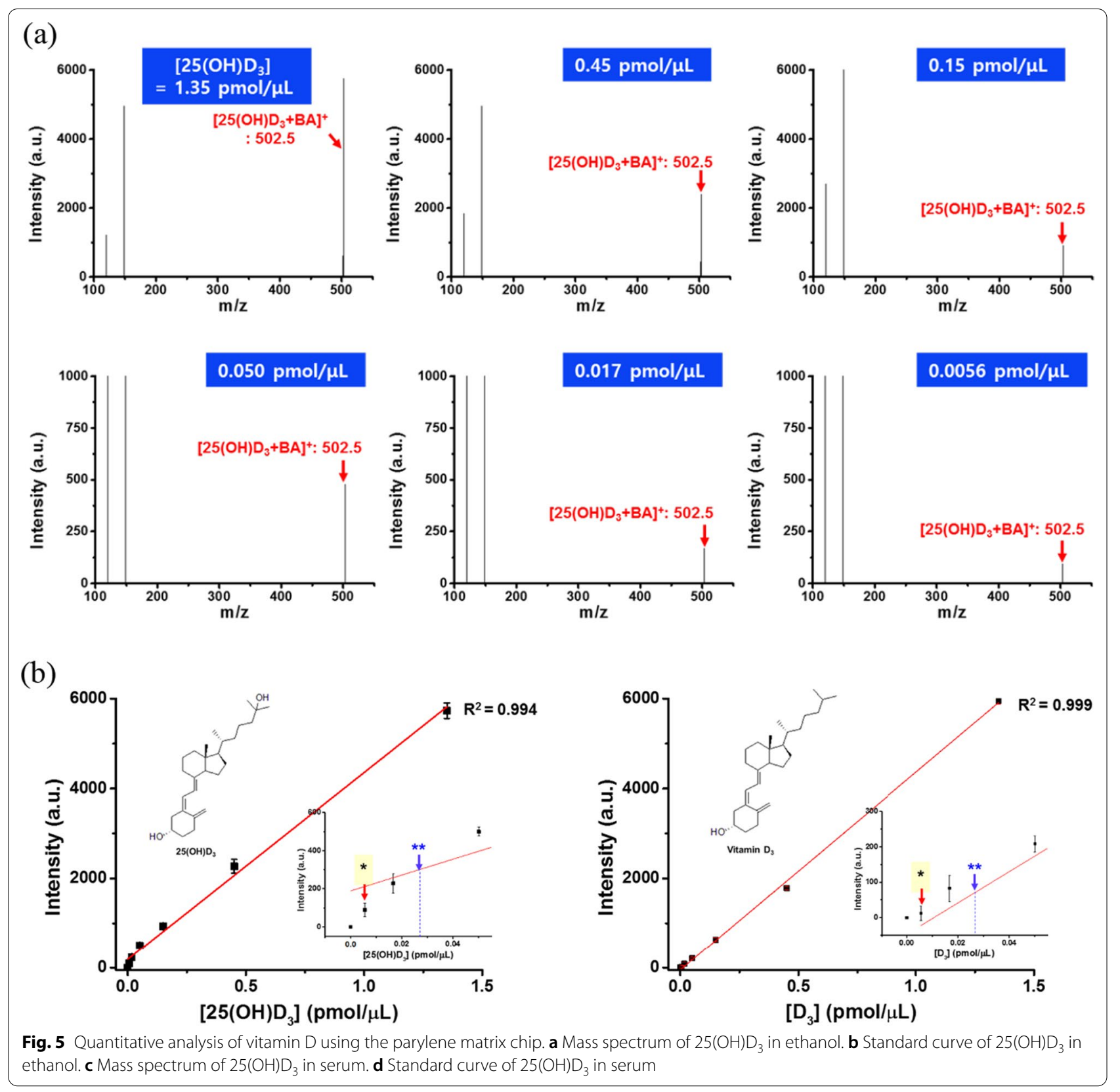

without matrix interference (Fig. 7b). The amount of vitamin $D_{3}$ was estimated to be $0.563 \mathrm{pmol} / \mu \mathrm{L}$ in energy drink $(0.65 \mathrm{pmol} / \mu \mathrm{L}$, according to the manufacturer's label, recovery $=86.6 \%$ ) and $0.942 \mathrm{pmol} / \mu \mathrm{L}$ for vitamin $\mathrm{D}_{3}$ tablet $(1.0 \mathrm{pmol} / \mu \mathrm{L}$ in the manufacturer's label, recovery $=94.2 \%$ ) from the standard curve, as shown in Fig. 7c. Thus, the amount of vitamin $\mathrm{D}_{3}$ from the measurement was well matched with that on the manufacturer's label, and the applicability of MALDI-TOF mass spectrometry based on the parylene matrix chip was estimated to be feasible for real sample analysis using energy drinks and vitamin $\mathrm{D}_{3}$ tablets.

\section{Conclusions}

Vitamin D deficiency is likely to play an important role in the high prevalence of rickets, osteoporosis, diabetes, and cardiovascular diseases. Vitamin D status is monitored by detecting $25(\mathrm{OH}) \mathrm{D}_{3}$ in serum due to its direct link to the vitamin $\mathrm{D}$ substrate and the long 


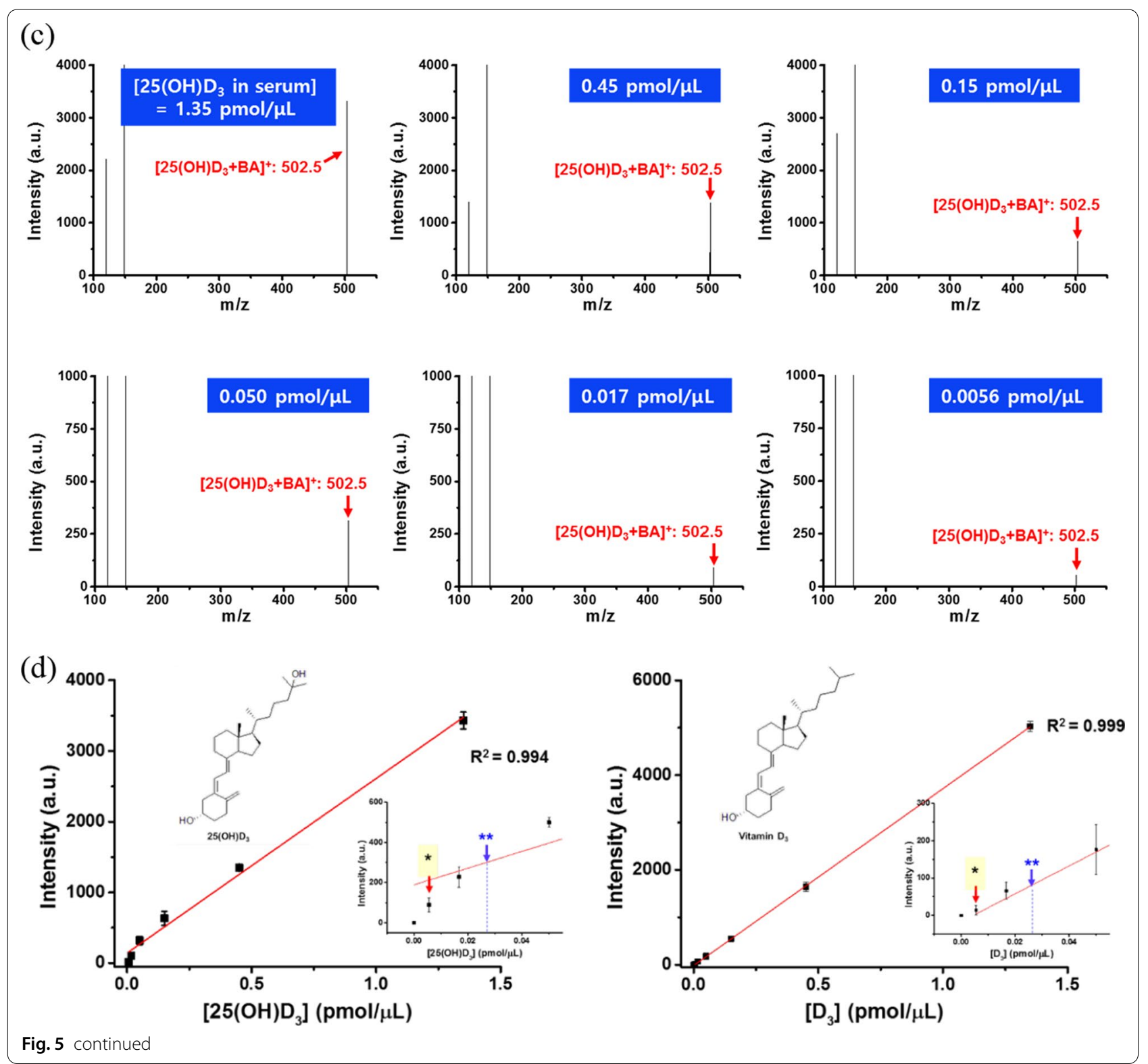

half-life of $25(\mathrm{OH}) \mathrm{D}_{3}$. The ionization efficiency of $25(\mathrm{OH}) \mathrm{D}_{3}$ is poor because of its hydrophobic nature and the lack of polar functional groups. Therefore, the rapid and selective chemical derivatization of $25(\mathrm{OH})$ $\mathrm{D}_{3}$ using $\mathrm{BA}$ was conducted to improve its detection sensitivity in MALDI-TOF mass spectrometry. A parylene chip was fabricated by depositing a thin and porous parylene $\mathrm{N}$-film on an organic matrix array to reduce the matrix background interference in the low mass-to-ratio range $(\mathrm{m} / z<500)$. The mixing zone of the parylene matrix chip was demonstrated by the Amplex Red assay, confirming that the mixing zone within the porous parylene film was formed below the surface of the parylene- $\mathrm{N}$ film. Based on the fluorescence image, the organic matrix below the parylene was homogeneously distributed, which corresponded to the enhanced shot-to-shot and spot-to-spot reproducibility. Various chemical derivatizations of vitamin D metabolites, such as acid-induced degradation, PTAD derivatization, and BA derivatization, were evaluated for their suitability to improve detectability in MALDI-TOF mass spectrometry. Among them, BA selectively and rapidly reacted with the alcohol group of vitamin $\mathrm{D}$ by nucleophilic addition, forming a hemiacetal salt, thereby displaying good ionization efficiency in MALDI-TOF mass spectrometry owing to its pre-charged form. The inter-spot 

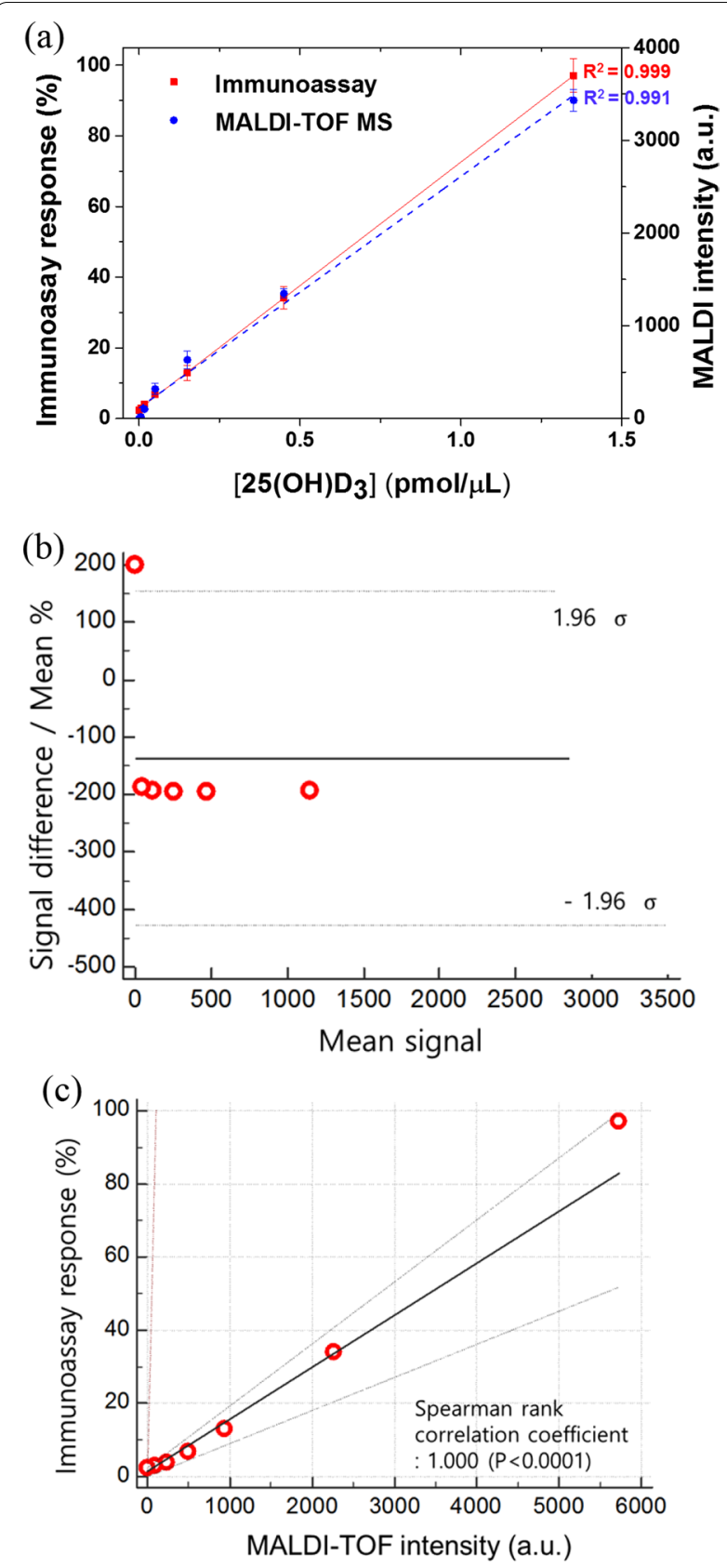

Fig. 6 Statistical analysis between enzyme immunoassay and MALDI-TOF mass spectrometry. a Comparison of $25(\mathrm{OH}) \mathrm{D}_{3}$ in serum by enzyme immunoassay and MALDI-TOF mass spectrometry. $\mathbf{b}$ Bland-Altman test. c Passing-Bablok regression

and intra-spot levels of reproducibility were confirmed to be within $5 \%$. Amount of $25(\mathrm{OH}) \mathrm{D}_{3}$ in ethanol was quantitatively analyzed by MALDI-TOF mass spectrometry based on a parylene matrix chip with good linearity $\left(r^{2}=0.994\right)$ and low LOD $(0.0056 \mathrm{pmol} /$ $\mu \mathrm{L})$. Serum $25(\mathrm{OH}) \mathrm{D}_{3}$ was extracted by liquid-liquid
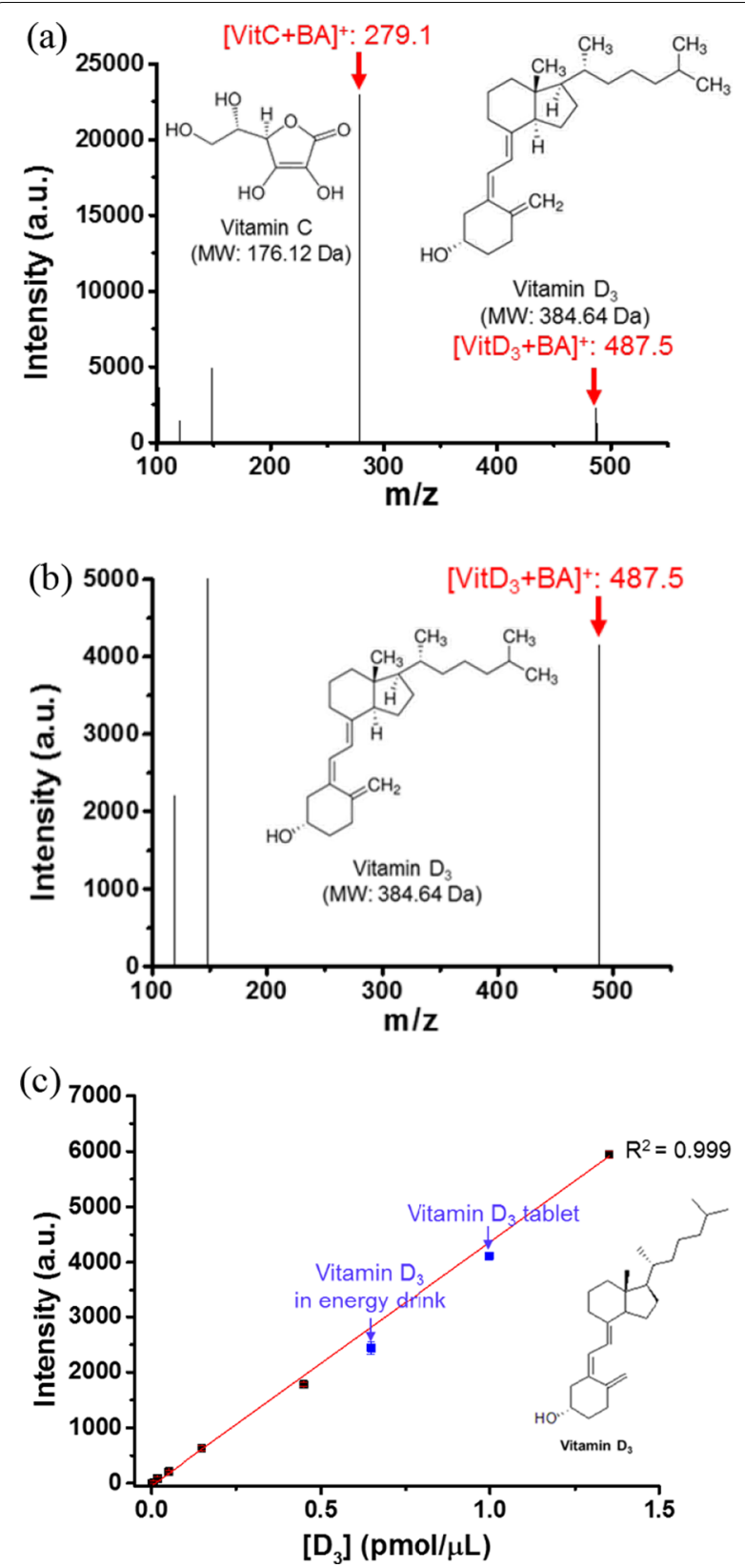

Fig. 7 Real sample analysis using MALDI-TOF mass spectrometry based on parylene matrix chip. a Mass spectrum of energy drink. $\mathbf{b}$ Mass spectrum of vitamin $D_{3}$ tablet. $\mathbf{c}$ Comparison of the estimated concentration using standard curve for vitamin $D_{3}$

extraction followed by quantification using MALDITOF mass spectrometry based on the parylene matrix chip. The intensity of the mass peak of $25(\mathrm{OH}) \mathrm{D}_{3}$ in serum was linearly correlated $\left(r^{2}=0.992\right)$ with the concentration of $25(\mathrm{OH})$ D3 in serum, and the LOD was low $(0.0056 \mathrm{pmol} / \mu \mathrm{L})$. The chemiluminescence binding 
assay and MALDI-TOF mass spectrometry results were statistically analyzed to determine the applicability of the method. Finally, the contents of an energy drink and vitamin $\mathrm{D}_{3}$ tablet were estimated using MALDI-TOF mass spectrometry based on a parylene matrix chip.

\section{Supplementary Information}

The online version contains supplementary material available at https://doi. org/10.1186/s40543-021-00313-2.

Additional file 1. Fig. S1. Analysis of the electrochemical property of parylene-N film by cyclic voltammetry with a redox couple of ferricyanide $\left(\mathrm{Fe}(\mathrm{CN})_{6}{ }^{3-/ 4-}\right)$. Fig. S2. Reproducibility of the parylene matrix chip. (a) Mass spectra of spot-to-spot reproducibility of $25(\mathrm{OH}) \mathrm{D}_{3}$. (b) Mass spectra of spot-to-spot reproducibility of $D_{3}$. (c) Mass spectra of shot-to-shot reproducibility of $25(\mathrm{OH}) \mathrm{D}_{3}$. (d) Mass spectra of shot-to-shot reproducibility of $D_{3}$. Fig. S3. Quantitative analysis of vitamin $D$ using the parylene matrix chip. (a) Mass spectrum of $D_{3}$ in ethanol. (b) Mass spectrum of $D_{3}$ in serum.

\section{Acknowledgements}

Not applicable.

\section{Authors' contributions}

Joo-Yoon Noh contributed to the experiment, data curation, and writing original draft. Moon-Ju Kim, Jong-Min Park, and Tae Gyeong Yun contributed to the experiment and data curation. Min-Jung Kang was involved in the supervision and review and editing. Jae-Chul Pyun was involved in the supervision, funding acquisition, writing — original draft, and review and editing. All authors read and approved the final manuscript.

\section{Funding}

This work is supported by the National Research Foundation of Korea [Grant Numbers: NRF-2020R1A2B5B01002187, NRF-2020R1A5A101913111 and NRF-2021R1A2C209370611].

\section{Declarations}

\section{Competing interests}

The authors declare that they have no competing interests.

\section{Author details}

${ }^{1}$ Department of Materials Science and Engineering, Yonsei University, 134 Shinchon-dong, Seodaemun-gu, Seoul 120-749, Korea. ${ }^{2}$ Korea Institute of Science and Technology (KIST), Seoul, Korea.

Received: 8 November 2021 Accepted: 27 December 2021

Published online: 10 January 2022

\section{References}

Agarwal VK. A new procedure for the isomerization of vitamin $D$ and its metabolites. J Steroid Biochem. 1990;35(1):149-50. https://doi.org/10. 1016/0022-4731(90)90160-T.

Ahn D-H, Kim H-j, Kim S-M, et al. MALDI-MS-based quantitative analysis of bioactive forms of Vitamin D in biological samples. Korean Chem Eng Res. 2020;58(1):106-12. https://doi.org/10.9713/kcer.2020.58.1.106.

Aronov PA, Hall LM, Dettmer K, et al. Metabolic profiling of major vitamin $D$ metabolites using Diels-Alder derivatization and ultra-performance liquid chromatography-tandem mass spectrometry. Anal Bioanal Chem. 2008;391(5):1917-30. https://doi.org/10.1007/s00216-008-2095-8.

Choi JW, Kim YJ, Lee JM, et al. Droplet-based synthesis of homogeneous gold nanoparticles for enhancing HRP-based ELISA signals. Biochip J. 2020;14(3):298-307. https://doi.org/10.1007/s13206-020-4307-z.
Cohen LH, Gusev AI. Small molecule analysis by MALDI mass spectrometry. Anal Bioanal Chem. 2002;373(7):571-86. https://doi.org/10.1007/ s00216-002-1321-z.

Ding S, Schoenmakers I, Jones K, et al. Quantitative determination of vitamin D metabolites in plasma using UHPLC-MS/MS. Anal Bioanal Chem. 2010;398(2):779-89. https://doi.org/10.1007/s00216-010-3993-0.

Enko D, Kriegshäuser G, Stolba R, et al. Method evaluation study of a new generation of vitamin D assays. Biochemia Med. 2015;25(2):203-12. https:// doi.org/10.11613/BM.2015.020.

Fleet JC. The role of vitamin D in the endocrinology controlling calcium homeostasis. Mol Cell Endocrinol. 2017. https://doi.org/10.1016/j.mce. 2017.04.008.

Guo Z, Zhang Q, Zou H, et al. A method for the analysis of low-mass molecules by MALDI-TOF mass spectrometry. Anal Chem. 2002;74(7):1637-41. https://doi.org/10.1021/ac010979m.

Ha M-Y, In Y-H, Maeng H-S, et al. Development of a matrix-prespotted plate for enhancing the reproducibility of serum glycan analysis by MALDI-TOFMS. Mass Spectrometry Lett. 2011;2(3):61-4. https://doi.org/10.5478/MSL. 2011.2.3.061.

Higashi T, Awada D, Shimada K. Simultaneous determination of 25-hydroxyvitamin D2 and 25-hydroxyvitamin D3 in human plasma by liquid chromatography-tandem mass spectrometry employing derivatization with a Cookson-type reagent. Biol Pharm Bull. 2001;24(7):738-43. https:// doi.org/10.1248/bpb.24.738.

Higashi T, Shibayama Y, Fuji M, et al. Liquid chromatography-tandem mass spectrometric method for the determination of salivary 25-hydroxyvitamin D 3: a noninvasive tool for the assessment of vitamin D status. Anal Bioanal Chem. 2008;391(1):229-38. https://doi.org/10.1007/ s00216-007-1780-3.

Holick MF. Vitamin D deficiency. New Engl J Med. 2007;357(3):266-81. https:// doi.org/10.1056/NEJMra070553.

Holick MF, Chen TC. Vitamin D deficiency: a worldwide problem with health consequences. Am J Clin Nutr. 2008;87(4):1080S-1086S. https://doi.org/ 10.1093/ajcn/87.4.1080S.

Hollis B, Napoli J. Improved radioimmunoassay for vitamin D and its use in assessing vitamin D status. Clin Chem. 1985;31(11):1815-9. https://doi. org/10.1093/clinchem/31.11.1815.

Jenkinson C, Taylor AE, Hassan-Smith ZK, et al. High throughput LC-MS/MS method for the simultaneous analysis of multiple vitamin $D$ analytes in serum. J Chromatogr B. 2016. https://doi.org/10.1016/j.jchromb.2016.01 049.

Jin $X$, Yang $X$, Yang $L$, et al. Autoxidation of isotachysterol. Tetrahedron. 2004;60(12):2881-8. https://doi.org/10.1016/j.tet.2004.01.075.

Kamen DL, Cooper GS, Bouali H, et al. Vitamin D deficiency in systemic lupus erythematosus. Autoimmun Rev. 2006;5(2):114-7. https://doi.org/10. 1016/j.autrev.2005.05.009

Kim H-J, Ji M, Song J, et al. Clinical utility of measurement of vitamin D-binding protein and calculation of bioavailable vitamin D in assessment of vitamin D status. Ann Lab Med. 2017a;37(1):34-8. https://doi.org/10.3343/ alm.2017.37.1.34.

Kim H-R, Bong J-H, Jung J, et al. An on-chip chemiluminescent immunoassay for bacterial detection using in situ-synthesized cadmium sulfide nanowires with passivation layers. Biochip J. 2020;14(3):268-78. https://doi.org/ 10.1007/s13206-020-4305-1.

Kim J-I, Noh J-Y, Kim M, et al. Newborn screening by matrix-assisted laser desorption/ionization mass spectrometry based on parylene-matrix chip. Anal Biochem. 2017b. https://doi.org/10.1016/j.ab.2017.04.021.

Kim JI, Park JM, Kang MJ, et al. Parylene-matrix chip for small molecule analysis using matrix-assisted laser desorption/ionization time-of-flight mass spectrometry. Rapid Commun Mass Spectrom. 2014a;28(3):274-80. https://doi.org/10.1002/rcm.6782.

Kim JI, Park JM, Noh JY, et al. Matrix-assisted laser desorption/ionization timeof-flight mass spectrometry of small volatile molecules using a parylenematrix chip. Rapid Commun Mass Spectrom. 2014b;28(21):2301-6. https://doi.org/10.1002/rcm.7025.

Loser K, Beissert S. Regulation of cutaneous immunity by the environment: an important role for UV irradiation and vitamin D. Int Immunopharmacol. 2009;9(5):587-9. https://doi.org/10.1016/j.intimp.2009.01.024.

Mahmoodani F, Perera CO, Fedrizzi B, et al. Degradation studies of cholecalciferol (vitamin D3) using HPLC-DAD, UHPLC-MS/MS and chemical 
derivatization. Food Chem. 2017. https://doi.org/10.1016/j.foodchem. 2016.09.146.

O'Rourke MB, Djordjevic SP, Padula MP. The quest for improved reproducibility in MALDI mass spectrometry. Mass Spectrom Rev. 2018;37(2):217-28. https://doi.org/10.1002/mas.21515.

Park CY, Moon S, Baek SH, et al. Development of detection methods for zinc pyrithione in polypropylene via simple extraction methods for quality control. Biochip J. 2020a;14(2):211-7. https://doi.org/10.1007/ s13206-020-4210-7.

Park J-M, Kim J-I, Song H-W, et al. Highly sensitive bacterial susceptibility test against penicillin using parylene-matrix chip. Biosens Bioelectron. 2015. https://doi.org/10.1016/j.bios.2015.04.059.

Park J-M, Kim J-I, Noh J-Y, et al. Hypersensitive antibiotic susceptibility test based on a $\beta$-lactamase assay with a parylene-matrix chip. Enzyme Microb Technol. 2017. https://doi.org/10.1016/j.enzmictec.2016.11.008.

Park J-M, Noh J-Y, Kim M-J, et al. MALDI-TOF mass spectrometry based on parylene-matrix chip for the analysis of lysophosphatidylcholine in sepsis patient sera. Anal Chem. 2019;91 (22):14719-27. https://doi.org/10.1021/ acs.analchem.9b04019.

Park J-M, Kim M-J, Noh J-Y, et al. Simultaneous analysis of multiple cancer biomarkers using MALDI-TOF mass spectrometry based on a parylenematrix chip. J Am Soc Mass Spectrom. 2020b;31(4):917-26. https://doi. org/10.1021/jasms.9b00102.

Seamark D, Trafford D, Makin H. A new procedure for the formation of isotachysterol derivatives of subnanomole quantities of ergocalciferol, cholecalciferol and its metabolites prior to gas liquid chromatography. J Steroid Biochem. 1980;13(9):1057-63. https://doi.org/10.1016/00224731(80)90137-5.

Shimada K, Mitamura K, Higashi T. Gas chromatography and high-performance liquid chromatography of natural steroids. J Chromatogr. 2001;935(1-2):141-72. https://doi.org/10.1016/S0021-9673(01)00943-8.

Smith KW, Flinders B, Thompson PD, et al. Spatial localization of vitamin $D$ metabolites in mouse kidney by mass spectrometry imaging. ACS Omega. 2020;5(22):13430-7. https://doi.org/10.1021/acsomega.0c01697.

Szaéjli E, Feheér T, Medzihradszky KF. Investigating the quantitative nature of MALDI-TOF MS. Mol Cell Proteomics. 2008;7(12):2410-8. https://doi.org/ 10.1074/mcp.M800108-MCP200.

Wei J, Buriak JM, Siuzdak G. Desorption-ionization mass spectrometry on porous silicon. Nature. 1999;399(6733):243-6. https://doi.org/10.1038/ 20400.

Wu C, Ifa DR, Manicke NE, et al. Rapid, direct analysis of cholesterol by charge labeling in reactive desorption electrospray ionization. Anal Chem. 2009;81(18):7618-24. https://doi.org/10.1021/ac901003u.

Zaikin VG, Halket JM. Derivatization in mass spectrometry-8. Soft ionization mass spectrometry of small molecules. Eur J Mass Spectrometry. 2006;12(2):79-115. https://doi.org/10.1255/ejms.798.

Zerwekh JE. The measurement of vitamin D: analytical aspects. Ann Clin Biochem. 2004;41 (4):272-81. https://doi.org/10.1258/0004563041201464.

Zerwekh JE. Blood biomarkers of vitamin D status. Am J Clin Nutr. 2008;87(4):1087S-1091S. https://doi.org/10.1093/ajcn/87.4.1087S.

\section{Publisher's Note}

Springer Nature remains neutral with regard to jurisdictional claims in published maps and institutional affiliations.

\section{Submit your manuscript to a SpringerOpen ${ }^{\odot}$ journal and benefit from:}

- Convenient online submission

- Rigorous peer review

- Open access: articles freely available online

- High visibility within the field

- Retaining the copyright to your article

Submit your next manuscript at $\boldsymbol{\nabla}$ springeropen.com 